\title{
Bacterial pneumonia as a suprainfection in young adults with measles
}

\author{
S. Loukides, P. Panagou, D. Kolokouris, N. Kalogeropoulos
}

\begin{abstract}
Bacterial pneumonia as a suprainfection in young adults with measles. S. Loukides, P. Panagou, D. Kolokouris, N. Kalogeropoulos. CERS Journals Ltd 1999.

ABSTRACT: The aim of this study was to report the clinical and laboratory characteristics of bacterial pneumonia related to measles infection, and also to assess any correlation between severity and time of onset.

Four hundred and twenty-four previously healthy young males (age $22 \pm 2.1$ yrs) were hospitalized with typical symptoms and signs of measles. One hundred and twelve $(26 \%)$ developed bacterial pneumonia on admission $(n=41)$, during their hospital stay $(n=20)$ or days after their discharge $(n=51)$ : groups $A, B$ and $C$, respectively.

Single lobar consolidation was the most common finding, accounting for $89 \%$ of cases. Pleural effusion was uncommon and associated in half of the cases with empyema. A microbiological diagnosis was made in 81 cases. Streptococcus pneumoniae (65 cases) and Klebsiella pneumoniae (9 cases) were the most commonly identified organisms. Patients from group $\mathrm{C}$ had significantly higher values of white blood cell count and erythrocyte sedimentation rate, and lower values of arterial oxygen tension $\left(14 \pm 0.8 \times 10^{9} \cdot \mathrm{L}^{-1}, 88 \pm 4 \mathrm{~mm}\right.$ and $6.3 \pm 0.4 \mathrm{kPa}(47 \pm 3 \mathrm{mmHg})$, respectively) than the other two groups. There were no deaths during the hospitalization period. The mean duration of hospital stay was $13 \pm 2.4$ days and was longer in the presence of $K$. pneumoniae infection $(19 \pm 1.6$ days). Six patients from group $C$ were admitted to the intensive care unit.

In conclusion, these data suggest that bacterial pneumonia associated with measles is not unusual in hospitalized adults, and it seems to be more severe when it occurs days after the onset of rash.

Eur Respir J 1999; 13: 356-360.
\end{abstract}

Measles remains a common childhood illness but epidemic patterns vary depending on population density and levels of acquired immunity. Prior to the vaccine era, measles occurred in epidemics of 3-4 months duration, every 2-5 years in temperate regions [1]. Except in isolated areas, most people had experienced the infection by the age of $20 \mathrm{yrs}$, and $90 \%$ of reported cases occurred in those $<10$ yrs of age [2]. Immunization programmes have markedly reduced the incidence of measles in developed countries. A routine two daily dose measles vaccine schedule is currently recommended, with the first dose at 15 months of age, or 12 months in high-risk areas, and the second dose at 6 yrs of age. The most common complication of the disease is pneumonia which is classified as primary measles virus pneumonia or secondary bacterial pneumonia [3].

Currently, over one-third of cases are reported in people aged $\geq 15$ yrs, particularly in relation to outbreaks in high school and college student populations [4]. Other reports have emphasized the increasing frequency in unvaccinated young adults in the military [5]. Previous reports have characterized measles-related bacterial pneumonia (MBP) as being common in children and having serious consequences [6]. These traditional views require reassessment in the young adult.
Pulmonary Department, 401 Army General Hospital, Athens, Greece.

Correspondence: S. Loukides

Smolika 2

Voula 16673

Athens

Greece

Fax: 3017494095

Keywords: Bacterial pneumonia measles

pulmonary complications

young adults

Received: April 301997

Accepted after revision October 301998
A large epidemic of measles in the Greek army has provided a unique opportunity to study bacterial pneumonia as a suprainfection in patients with measles and also to investigate if there is a correlation between its severity and its onset.

\section{Materials and methods}

An epidemic of 1,400 cases $(15 \%$ of the entire epidemic population) of clinical measles occurred in the Greek army between January 1996 and July 1996. Of these cases, 424 previously healthy young males (mean age $22 \pm 2 \mathrm{yrs}$ ), were admitted to the infectious diseases ward at the Army General Hospital of Athens for the following reasons: 1) in order to protect the rest of the army population from virus transmission; 2) more severe clinical course than those not admitted; and 3) difficulty in the administration of appropriate primary healthcare to the epidemic population in the army areas.

The diagnosis of measles was established by a history of a typical prodrome and physical signs including maculopapular rash, conjunctivitis, pharyngitis, Koplik spots and lymphadenopathy. In 24 cases there was some debate about the clinical diagnosis. In those patients the diagnosis was substantiated by elevated immunoglobulin-M (IgM) 
levels to the measles virus in the serum measured by enzyme immunoassay. No patient had received the second dose of measles vaccine. Of the 424 patients, $126(30 \%$, mean age $22 \pm 1 \mathrm{yrs}$ ) were admitted to our department with a diagnosis of "pneumonia". Using the criteria of MYou et al. [7], seven patients were believed to have primary measles virus pneumonia (MVP) and were excluded from the study. Seven of the remaining patients were also excluded for having adenovirus-related pneumonia (one), mycoplasma pneumonia (four) and tuberculosis (two). The remaining 112 patients were found to have MBP on the basis of the following criteria [8]: 1) productive cough with purulent sputum; 2) consolidation of infectious origin on chest radiograph; 3) increase of white blood cell (WBC) count; 4) clinical course suggesting bacterial infection; and 5) Gram-stain of the sputum specimen suggestive of bacterial infection. These patients were divided into three groups according to the period in which MBP occurred. Group A $(n=41)$ consisted of those patients who had MBP on admission. In group B $(n=20)$, patients were normal on admission but changes compatible with MBP were found during their hospital stay. In the 51 patients of group $\mathrm{C}$, MBP was found days after their hospital discharge (mean time $8 \pm 1.2$ days). Four patients from those with elevated IgM levels to the measles virus developed MBP (group $\mathrm{A}=2$, group $\mathrm{C}=2$ ).

The following measurements were recorded during the patient's clinical and laboratory evaluation.

\section{Chest radiograph}

All chest radiographs were evaluated for: 1) the extent of consolidation; and 2) the extent of radiographic resolution after diagnosis and treatment. All 424 patients received a chest radiograph immediately on admission. Patients from group $\mathrm{B}$ and $\mathrm{C}$ had a normal chest radiograph on admission. Our policy was to perform a second chest radiograph in all the patients with measles before discharge from the hospital. In patients from group $\mathrm{C}$ this radiograph was also normal. A sinus radiograph was performed when a diagnosis of MBP was established.

\section{Symptoms and physical findings}

Symptoms (cough, sputum production, and dyspnoea) were recorded using a severity score scale $0-3(0=$ none, $1=$ mild, $2=$ moderate, and $3=$ severe). Temperature, cardiac frequency, respiratory frequency, and blood pressure were the parameters analysed.

\section{Microbiology/antibiotic treatment}

Nasopharyngeal, sputum and blood specimens for bacteria were obtained at the time of diagnosis of MBP and before antibiotic treatment was started. In patients admitted to the intensive care unit (ICU) two more blood cultures were routinely collected although antibiotic treatment had already been started. To attribute the cause of pneumonia, sputum culture for bacteria was used in most cases. Sputum cultures were accepted only if they agreed with a Gram-stain. All sputum samples were representative of lower respiratory tract secretions as they contained $\geq 25$ neutrophils and $\leq 10$ epithelial cells per microscopic field. Blood cultures were only used if they were positive on admission. In patients with empyema, pleural fluid culture of bacteria was used.

\section{Blood tests}

Venous blood was sampled for urea, creatinine, electrolytes, albumin, liver function tests (serum glutamate oxaloacetate transaminase (SGOT), serum glutamate pyruvate transaminase (SGPT), and alkaline phosphatase (ALP)), full blood count (FBC), erythrocyte sedimentation rate (ESR). Arterial blood gases were analysed before starting oxygen therapy (blood gas analyser ABL 500, Radiometer, Copenhagen, Denmark). Antibody titres to atypical pneumonia micro-organisms and viruses were measured in all the 126 patients with suspected pneumonia. Antibody titres to influenza A and B viruses, adenoviruses. Mycoplasma pneumoniae, Chlamydia pneumoniae, Rickettsiae and Legionella pneumophila were compared between the acute and convalescent phase of the disease. A 4-fold rise or a single titre $\geq 1: 128$ were considered significant of a recent infection.

\section{Outcome}

Outcome was assessed by survival, clinical complications related to pneumonia and duration of hospital stay. Data are expressed as mean \pm SEM. Two-way analysis of variance (ANOVA) was used for statistical analysis. A significant difference between samples was accepted at $\mathrm{p}<$ 0.05 .

\section{Results}

\section{Radiographic findings}

Radiographic findings are summarized in table 1. Pulmonary consolidation was confined to a single lobe in $89 \%$ of the patients. Patients from group C were found to have a higher percentage of two lobes affected $(18 \%, p<$ $0.001)$. Multilobar findings were mainly reported in patients with pneumonia related to klebsiella. Radiographic presentation of sinusitis was mainly found in patients of group C (64\%). Six patients from group $\mathrm{C}$ and one from group A had a history of previous sinus disease. Pleural effusion was found equally among the three groups. Using the criteria of LigHT et al. [9], it was characterized as parapneumonic in three cases (one in each group) and as empyema in two cases in group $\mathrm{C}$ and in one case in group A. Delayed radiographic resolution was found in patients of group $\mathrm{C}$ (table 1). These findings were mainly associated with a high percentage of sinusitis and also with pneumonia related to klebsiella. Separating these two subgroups from the total number of patients in group $\mathrm{C}$, on average, a radiographic resolution of $7.8 \pm 1$ weeks and $8.3 \pm 1$ weeks was found, respectively. The remaining patients had a radiographic resolution, on average, of $6 \pm 1$ weeks. These three values were higher than in the other two groups $(\mathrm{p}<0.001, \mathrm{p}<0.0001, \mathrm{p}<0.01$ respectively). 
Table 1. - Radiographic findings in patients with measlesrelated bacterial pneumonia (MBP)

\begin{tabular}{lccc}
\hline & $\begin{array}{c}\text { Group A } \\
(\mathrm{n}=41)\end{array}$ & $\begin{array}{c}\text { Group B } \\
(\mathrm{n}=20)\end{array}$ & $\begin{array}{c}\text { Group C } \\
(\mathrm{n}=51)\end{array}$ \\
\hline Number of lobes involved & & & \\
One & 39 & 19 & 42 \\
Two & 2 & 1 & $9^{\dagger}$ \\
$\quad$ Three or more & 0 & 0 & 0 \\
Pleural effusion & 3 & 1 & 3 \\
Sinusitis & 2 & 3 & $27^{\ddagger}$ \\
Time of radiographic & $5 \pm 1$ & $5 \pm 1$ & $7.5 \pm 1.5^{\dagger}$ \\
resolution weeks* & & & \\
\hline
\end{tabular}

*Data are presented as mean \pm SEM. Group A: MBP on admission; Group B: MBP developed during hospital stay; Group C: MBP developed days after discharge. ${ }^{\dagger}: \mathrm{p}<0.001$ versus the other two groups; $: \mathrm{p}<0.002$ versus the other two groups

\section{Symptoms and physical findings}

The values of symptom severity scores and of physical findings are presented in table 2 . Cough $(89 \%)$ and sputum production $(91 \%)$ were the most commonly reported respiratory symptoms. When comparing the dyspnoea score, patients from group $\mathrm{C}$ had, on average, higher values than the other two groups $(1.01 \pm 0.2, \mathrm{p}<0.001)$. When the nine patients with klebsiella-related pneumonia were looked at, the dyspnoea score was significantly higher than the remaining 42 patients of this group $(2.2 \pm 0.3 \mathrm{ver}$ sus $0.75 \pm 0.3, \mathrm{p}<0.0002)$. Temperature $>37.5^{\circ} \mathrm{C}$ was recorded in 104 patients. Systolic and diastolic hypotension $(<100 \mathrm{mmHg}$ and $<70 \mathrm{mmHg}$, respectively) were noted in six patients from group $\mathrm{C}$ who required admission to the ICU. In the same patients an increase in cardiac frequency and respiratory frequency was also found (125 13 beats $\cdot \mathrm{min}^{-1}$ and $33 \pm 1.7$ breaths $\cdot \mathrm{min}^{-1}$, respectively).
Delayed resolution was recorded in patients from group $\mathrm{C}$ $(2.8 \pm 0.1$ weeks, $\mathrm{p}<0.0001)$.

\section{Microbiology/antibiotic treatment}

A satisfactory sputum sample was obtained in 95 patients $(85 \%)$. A microbiological diagnosis was established in 81 cases $(72 \%)$. The 14 missing patients were taking oral antibiotics on admission. Sputum Gram-stain examination predicted the correct pathogen in all the remaining 81 patients. The predominant pathogen was $S$. pneumoniae (65 cases), followed by $K$. pneumoniae (nine cases) and Staphylococcus aureus (three cases) (table 3). Nasopharyngeal specimen examination predicted the correct pathogen in 49 patients and was misleading in the remaining 32 patients. In all the cases with empyema S. pneumoniae was isolated in pleural fluid. This finding was in agreement with the Gram-stain and sputum culture for bacteria in the same patients. All blood cultures (before antibiotic treatment) for bacteria were negative. Presence of bacteraemia was found in six patients from group C (all admitted to ICU) with MBP related to klebsiella although antibiotic treatment had already been started. Treatment with antibiotics was instituted in all patients. The most frequently prescribed antibiotics were co-amoxiclav (54 cases), benzylpenicillin (15 cases), erythromycin (12 cases) and cefamandole (11 cases).

\section{Blood tests}

The results of haematology tests and blood gases are listed in table 2. Patients from group $\mathrm{C}$ were found to have lower values of arterial oxygen tension $\left(\mathrm{Pa}, \mathrm{O}_{2}\right)$ in relation to the other two groups $(6.3 \pm 0.4 \mathrm{kPa}(47 \pm 3 \mathrm{mmHg}) \mathrm{p}<$ 0.002). The same patients were found to have an increase

Table 2. - Symptom scores, physical findings, haematology results and blood gases in patients with measles-related bacterial pneumonia

\begin{tabular}{|c|c|c|c|c|}
\hline & Group A $(n=41)$ & Group B (n=20) & Group C $(\mathrm{n}=51)$ & p-value \\
\hline \multicolumn{5}{|l|}{ Symptom score } \\
\hline Cough & $1.8 \pm 0.2$ & $1.7 \pm 0.3$ & $1.9 \pm 0.6$ & NS \\
\hline Sputum production & $2 \pm 0.2$ & $1.9 \pm 0.6$ & $2.1 \pm 0.3$ & NS \\
\hline Dyspnoea & $0.2 \pm 0.1$ & $0.3 \pm 0.1$ & $1.01 \pm 0.1$ & $<0.001$ \\
\hline Total symptom score & $1.4 \pm 0.1$ & $1.3 \pm 0.3$ & $1.7 \pm 0.3$ & NS \\
\hline $\begin{array}{l}\text { Time for symptoms } \\
\text { to resolve weeks }\end{array}$ & $1.5 \pm 0.1$ & $1.6 \pm 0.2$ & $2.8 \pm 0.1$ & $<0.0001$ \\
\hline \multicolumn{5}{|l|}{ Physical findings } \\
\hline Temperature ${ }^{\circ} \mathrm{C}$ & $37.7 \pm 0.4$ & $38.01 \pm 0.6$ & $38.2 \pm 0.3$ & NS \\
\hline Cardiac frequency beats $\cdot \mathrm{min}^{-1}$ & $89 \pm 11$ & $93 \pm 12$ & $99 \pm 18$ & NS \\
\hline Respiratory rate breaths $\cdot \min ^{-1}$ & $17 \pm 2$ & $15 \pm 3$ & $18 \pm 2$ & NS \\
\hline DBP mmHg & $79 \pm 7$ & $77 \pm 6$ & $71 \pm 5.8$ & NS \\
\hline SBP mmHg & $117 \pm 7.3$ & $115 \pm 5.3$ & $109 \pm 6$ & NS \\
\hline \multicolumn{5}{|l|}{ Blood gases } \\
\hline$P \mathrm{a}, \mathrm{O}_{2} \mathrm{mmHg}$ & $67 \pm 11$ & $71 \pm 8$ & $47 \pm 3$ & $<0.002$ \\
\hline $\mathrm{Pa}_{\mathrm{a}, \mathrm{CO}_{2} \mathrm{mmHg}}$ & $38 \pm 0.7$ & $37 \pm 1.7$ & $35 \pm 18$ & NS \\
\hline $\mathrm{pH}$ & $7.42 \pm 0.1$ & $7.39 \pm 0.6$ & $7.44 \pm 0.5$ & NS \\
\hline \multicolumn{5}{|l|}{ Haematology } \\
\hline $\mathrm{WBC} \times 10^{9} \cdot \mathrm{L}^{-1}$ & $9.2 \pm 1.3$ & $10.1 \pm 0.3$ & $14.4 \pm 0.4$ & $<0.0001$ \\
\hline ESR mm & $62 \pm 3$ & $71 \pm 3$ & $88 \pm 4$ & $<0.01$ \\
\hline $\mathrm{Hb} g \cdot \mathrm{dL}^{-1}$ & $12 \pm 1.1$ & $12.4 \pm 1.3$ & $11 \pm 0.9$ & NS \\
\hline
\end{tabular}

Data are expressed as mean \pm SEM. DBP: diastolic blood pressure; SBP: systolic blood pressure; WBC: white blood cells; ESR: erythrocyte sedimentation rate; $\mathrm{Hb}$ : haemoglobin; $\mathrm{Pa}, \mathrm{O}_{2}:$ arterial oxygen tension; $\mathrm{Pa}, \mathrm{CO}_{2}$ : arterial carbon dioxide tension. For definition of groups see footnote to table 1 . $(1 \mathrm{mmHg}=0.133 \mathrm{kPa}$. $)$ 
Table 3. - Microbiological findings in patients with measles-related bacterial pneumonia

\begin{tabular}{lccc}
\hline & $\begin{array}{c}\text { Group A } \\
(\mathrm{n}=34)\end{array}$ & $\begin{array}{c}\text { Group B } \\
(\mathrm{n}=12)\end{array}$ & $\begin{array}{c}\text { Group C } \\
(\mathrm{n}=35)\end{array}$ \\
\hline Streptococcus pneumoniae & 32 & 10 & 23 \\
Klebsiella pneumoniae & 0 & 0 & 9 \\
Staphylococcus aureus & 2 & 0 & 1 \\
Pseudomonas aeruginosa & 0 & 0 & 1 \\
Moraxella catarrhalis & 0 & 1 & 1 \\
Haemophilus influenzae & 0 & 1 & 0 \\
\hline
\end{tabular}

For definition of groups see footnote to table 1 .

in WBC count and ESR compared to the other two groups $\left(14.4 \pm 0.4 \times 10^{9} \cdot \mathrm{L}^{-1}, 88 \pm 4 \mathrm{~mm}\right.$, respectively $\left.\mathrm{p}<0.0002\right)$. WBC and ESR values in $K$. pneumoniae patients were $18 \pm 0.7 \times 10^{9} \cdot \mathrm{L}^{-1}$ and $114 \pm 4 \mathrm{~mm}$, respectively. These values were higher than the 42 remaining patients of group $\mathrm{C}$ $\left(13.4 \pm 0.5 \times 10^{9} \cdot \mathrm{L}^{-1}, 97 \pm 4 \mathrm{~mm}, \mathrm{p}<0.002\right)$. Finally, the values for these 42 patients were higher than the other two groups $(p<0.001)$. There was a mild elevation in liver function tests which was equally presented among the three groups. No abnormal values were found in renal function tests, electrolytes or albumin.

\section{Outcome}

All the patients survived to hospital discharge. Admission to ICU was required for six patients (all from group C with klebsiella-related pneumonia). One required mechanical ventilation. A small pericardial effusion was reported in one patient (group C). The mean duration of hospital stay was $13 \pm 2.4$ days and it was longer in group $C$ patients ( $15 \pm 2.1$ days). This was due to klebsiella-related pneumonia, which resulted in the longest duration of stay $(19 \pm 1.6$ days). Finally, no particular findings in the four patients with elevated IgM levels to measles virus were found.

\section{Discussion}

It was shown that MBP was not unusual in adults and also that a severity assessment based on variables obtained from history, laboratory and radiographic data, microbiology and finally outcome, identified a subgroup of patients with increased risk of a severe clinical condition. This group mainly consisted of patients in whom MBP occurred days after the onset of the rash.

Although MBP is regarded as a common complication of measles, its frequency appears to be highly variable. Rates of 3.5-50\% have been reported in both children and young adults by different authors [10,11]. Few studies have assessed the frequency of MBP complicating measles in young adults. In a group of naval recruits, MBP occurred in $50 \%$ of patients, but the study population consisted of only 32 young adults [12]. The present study confirms a lower percentage for those affected $(7 \%)$ and hospitalized $(24 \%)$ but the study population was less restrictive than that reported by other studies as it included more and older patients.

Radiographic, laboratory and clinical findings of patients with MBP are generally similar. It has been reported
[10] that measles patients with bacterial suprainfection were more likely to have multilobar infiltrates, but this was not a useful clinical observation. In the present study, multilobar findings tended to appear with resolution of the rash and were mainly related to the micro-organism responsible. Pleural effusion was present in $16 \%$ of cases. These findings are consistent with those of other observers [13]. Radiological abnormalities of the paranasal sinuses are very commonly observed in MBP patients [14]. Up to $30 \%$ of young adults with measles-related MBP have sinusitis [15]. A similar percentage was found in the present study with patients coming mainly from the third group. Resting hypoxaemia, which was found in patients from group $\mathrm{C}$, was related to ventilation impairment through an extension of radiographic findings and the presence of sinusitis which usually affects ventilation by increasing bronchial secretions due to post-nasal mucopurulent discharge. The severity score of dyspnoea identified a subgroup of patients at increased risk of severe clinical course. This valuable sign needs greater emphasis as an indicator of severity of MBP, mainly when it is recorded after the resolution of rash.

The range of micro-organisms reported as being responsible for MBP varies between the studies $[12,16]$. The role of Neisseria meningitidis serogroup Y as a cause of suprainfection was first suggested in Air Force recruits with MBP [17]. HenNeman et al. [18] noted the frequent occurrence of streptococcus and $S$. aureus but recorded no cases of $N$. meningitidis. The range of causative organisms identified was similar to the present study although there are some differences in the relative proportions. The high incidence of klebsiella infection was presumably because the study was carried out during a cyclic epidemic. It is interesting that in one study, $20 \%$ of patients improved without antibiotics [12]. In contrast, the present authors believe that antibiotic treatment should be instituted without delay, particularly in those patients having signs of severe pneumonia. Transtracheal aspiration was found to be indispensable in the microbiological diagnosis of MBP [19], but the study population consisted of children who are usually unable to produce sputum. In the present study, the absence of positive blood cultures on admission leads to the plausible explanation that only in the empyema case was the identified bacterium the cause of the pneumonia. It could also be argued that all the other cases were cases of MVP with the isolated bacteria representing bronchial colonization. Most cases of MVP are probably usually found in the acute phase of the disease and also have completely different clinical and radiological appearances $[3,7]$. Partial support of this theory was given by the seven possible cases of MVP found in the initial study population who had typical findings of MVP. These findings were completely different compared to the present study population. Gram-stain of sputum has been the cornerstone of microbiological investigation for community-acquired pneumonia for many years. Although its diagnostic efficacy is still under external consideration, it is a simple and rapid method for identifying the cause of pneumonia in patients not previously treated with antibiotics and able to produce a good sample without saliva [8]. Sputum culture is of less value due to contamination with oral flora. Diagnostic acceptance of sputum culture is based on its agreement with the Gram-stain. Samples in the 
present study fulfilled the above criteria and offered a high diagnostic yield.

Mortality from MBP, with other measles complications, increases with malnutrition and young age [20,21]. Data collected in developing countries suggest that nutritional status and age are important factors contributing to mortality rates $[22,23]$. In previously healthy young adults with normal nutritional status, however, MBP appeared to be relatively benign accounting for no deaths in 32 cases reported by OLSON and Hodges [12] and 35 cases reported by GREMILLION and CRAWFORD [10]. Similar findings were recorded in the present study. The data confirm previous reports which demonstrate that hospitalization in MBP is prolonged [10]. This finding may be related to virus-induced immunosuppression which leads to delayed radiographic and clinical improvement. The data also suggest that there is a strong relationship between the onset of the rash and the clinical severity of the disease. The high incidence of MBP after hospital discharge may be a result of having to hospitalize all active duty personnel with measles. This leads to the plausible explanation that if patients with measles were not admitted to hospital in the first place then the majority of cases in group $C$ would be prevented as most of them were probably suffering from a nosocomial infection. However, the increased risk of a severe clinical course which was found after the onset of the rash in group $\mathrm{C}$ patients confirms previous reports in which a severe clinical course was related to progressive virus-induced immunosuppression, damage to respiratory epithelium, and depressed phagocytic and bactericidal capacities of polymorphonuclear cells that usually occurred after the onset of the rash [24, 25].

Measles-related bacterial pneumonia was shown not to be unusual in young adults, with a more severe clinical course when it occurs after the onset of the rash. Unlike children and compromised hosts, deaths are rare and measles-related bacterial pneumonia generally has a benign outcome.

\section{References}

1. Chen RT, Goldbaum GM, Wassilak SG, Markowtiz LE, Orenstein WA. An explosive point-source measles outbreak in a highly vaccinated population. Am J Epidemiol 1989; 129: 173-182.

2. Mason WH, Ross LA, Lanson J, Wright HT. Epidemic measles in the postvaccine era: evaluation of epidemiology, clinical presentation and complications during an urban outbreak. Pediatr Infect Dis J 1993; 12: 42-48.

3. Editorial. Pulmonary complications of measles. $\mathrm{Br}$ Med J 1976; 2: 777-778.

4. Hersh BS, Markowitz LE, Maes EF. The geographic distribution of measles in USA, 1980 through 1989. J Am Med Assoc 1992; 267: 1933-1941.

5. Atkinson WL, Markowitz LE, Adams NC, Seastrom GR. Transmission of measles in medical setting-USA, 19851989. Am J Med 1991; 91: 320-324.

6. Berman S. Epidemiology of acute respiratory infections in children of developing countries. Rev Infect Dis 1991; 13: Suppl. 6, 454-462.
7. Myou S, Fujimura M, Yasui M, Ueno T, Matsuda T. Bronchoalveolar lavage cell analysis in measles viral pneumonia. Eur Respir J 1993; 6: 1437-1442.

8. Torres A, Woodhead A. Definition and classification of community-acquired and nosocomial pneumonias. Eur Respir Mon 1997; 2 (3): 1-12.

9. Light RW, McGregor MI, Luchsinger PC, Ball WC. Pleural effusions: the diagnostic separation of transudates and exudates. Ann Int Med 1972; 77: 507-512.

10. Gremillion DH, Crawford GE. Measles pneumonia in young adults. Am J Med 1981; 71: 539-542.

11. Abramson O, Dagan R, Tal A, Sofer S. Severe complications of measles requiring intensive care in infants and young children. Arch Pediatr Adolesc Med 1995; 149: $1237-1240$.

12. Olson RW, Hodges GR. Measles pneumonia-bacterial suprainfection as a complicating factor. J Am Med Assoc 1975; 232: 363-365.

13. Akamaguna AI, Odita JC. The radiological aspects of chest complication in childhood measles. Ann Trop Paediatr 1982; 2: 129-132.

14. Humphrey MA, Simpson GT, Grindlinger GA. Clinical characteristics to nosocomial sinusitis. Ann Otol Rhinol Laryng 1987; 96: 687-690.

15. Leibovici L, Sharir T, Kalter-Leibovici O, Alpert G, Epstein LM. An outbreak of measles among young adults. Clinical and laboratory features in 461 patients. $J$ Adolesc Health Care 1988; 9: 203-207.

16. Jonnson AW, Osinusi K, Aderele WI, Adeyemi-Doro FA. Bacterial etiology of acute respiratory infections in preschool Nigerian children and comparative predictive features of bacteraemic and non bacteraemic illness. $J$ Trop Pediatr 1993; 39: 97-106.

17. Koppes G, Gephart RG, Ellenbogen C. Neisseria meningitidis group Y pneumonia in Air Force recruits. Am J Med 1977; 62: 661-666.

18. Henneman PL, Birnbaumer DM, Cairns CB. Measles pneumonitis. Ann Emerg Med 1995; 26: 278-282.

19. Gerson AA. Measles virus. In: Mandell GL, Douglas RG, Bennett JE, eds. Principles and Practice of Infectious Diseases, 3rd edn. New York, Churchill Livingstone, 1990; pp. 1279-1286.

20. Horwitz O, Grunfeld K, Lysgard B, Kjeldsen K. The epidemiology and natural history of measles in Denmark. Am J Epidemiol 1974; 100: 136-149.

21. The National Vaccine Advisory Committee. Special communication. The measles epidemic. Problems barriers and recommendations. J Am Med Assoc 1991; 266: 15471542.

22. Rasmi A, Guha DK, Khanduja PC. Postmeasles pulmonary complications in children. Indian Pediatr 1971; 8: $834-838$

23. Cattaneo A. Current role of vaccination in preventing acute respiratory infections in children in developing countries. Monaldi Arch Chest Dis 1994; 49: 57-60.

24. Griifin DA, Ward BJ, Jauregui E, Johnson RT, Vaisberg A. Natural killer cell activity during measles. Clin Exper Immunol 1990; 81: 218-224.

25. Thatte UM, Gangal PS, Kulkarni MR, Anklesaria PS, Kumta NB, Dahanucar SA. Polymorphonuclear and monocyte functions in measles. J Trop Pediatr 1991; 37: 6770. 